\title{
Fear of movement (kinesiophobia) - an underestimated problem in Polish patients at various stages of coronary artery disease
}

\author{
Józefa Dąbek ${ }^{1, A-F \oplus}$, Andrzej Knapik ${ }^{2, A, C-D, F \oplus}$, Weronika Gallert-Kopyto ${ }^{3, D \oplus}$, Anna Brzęk $k^{4, D, F} \oplus$, \\ Joanna Piotrkowicz ${ }^{1, B \oplus}$, Zbigniew Gąsior ${ }^{1, E \oplus ~}$ \\ ${ }^{1}$ School of Health Sciences, Katowice, Department of Cardiology, Medical University of Silesia, Katowice, Poland \\ ${ }^{2}$ School of Health Sciences, Katowice, Department of Adapted Physical Activity and Sport, Chair of Physiotherapy, \\ Medical University of Silesia, Katowice, Poland \\ ${ }^{3}$ School of Health Sciences, Katowice, Department of Kinesiology, Chair of Physiotherapy, Med-ical University of Silesia, \\ Katowice, Poland \\ ${ }^{4}$ School of Health Sciences, Katowice, Department of Physiotherapy, Chair of Physiotherapy, Medical University of Silesia, \\ Katowice, Poland \\ A - Research concept and design, B - Collection and/or assembly of data, C - Data analysis and interpretation, \\ $D$ - Writing the article, $E$ - Critical revision of the article, $F$ - Final approval of article
}

Dąbek J, Knapik A, Gallert-Kopyto W, Brzęk A, Piotrkowicz J, Gąsior Z. Fear of movement (kinesiophobia) - an underestimated problem in Polish patients at various stages of coronary artery disease. Ann Agric Environ Med. 2020; 27(1): 56-60. doi: 10.26444/aaem/106143

\section{Abstract}

Introduction. The importance of the problem of reduced motor activity in the prophylaxis and treatment of many diseases has resulted in numerous adaptations of a diagnostic tool, both for the disease and for linguistic and cultural versions. This also applies to cardiovascular diseases. The significance of the problem, and encouraging results of several studies, have led to a wider use of this tool. This also applies to people suffering cardiologically in Poland, where this problem is poorly understood. This was the inspiration to undertake research on the explanation of the reasons for the limitation in the activation of cardiac patients.

Objective. The aim of the study was to determine the level of kinesiophobia in patients with CAD, and to assess its possible association with physical activity (PA), socio-demographic determinants and morbidity.

Materials and method. The study was cross-sectional and included 217 hospitalized patients with CAD: 94 women and 123 men; aged 67.39 years. PA was assessed using the short version of IPAQ, and kinesiophobia was assessed using TSK Heart in Polish adaptation. TSK HeartIPAQ correlations were found.

Results. More than $70 \%$ of the patients revealed high levels of kinesiophobia (TSK $>37$ points). There were no TSK associations with gender, BMI, socio-demographic variables, other conditions and duration of cardiovascular disease. The disease is the main cause of kinesiophobia and regardless of its nature, negatively affects the level of PA.

Conclusions. The quality of life of patients with CAD at various stages and the effectiveness of cardiolog-ical rehabilitation are conditioned by PA.

\section{Key words}

physical activity, CAD, kinesiophobia, Tampa Scale for Kinesiophobia Heart

\section{Abbreviations}

CAD - Cardiovascular diseases, PA - Physical Activity, IPAQ - International Physical Activity Questionnaire, TSK - Tampa Scale for Kinesiophobia

\section{INTRODUCTION}

Cardiovascular diseases are one of the leading causes of death and health loss, not only in Poland, but also in Europe and worldwide $[1,2,3]$. The implementation of modern diagnostic methods, development of invasive cardiology, use of new surgical techniques and a number of other projects, such as development of telemedicine or re-education of patients, have resulted not only in a decrease in mortality, but also an increase in the need for rehabilitation [4]. Cardiovascular rehabilitation should combine physical

Address for correspondence: Anna Brzęk, Medical University of Silesia in Katowice, Medyków 12, 40-752 Katowice, Poland

E-mail: abrzek@sum.edu.pl

Received: 04.02.2019; accepted: 26.03.2019;first published: 10.04.2019 training and the implementation of secondary cardiovascular disease prevention and - where appropriate - psychological therapy [5].

Optimal level of physical activity $\{\mathrm{PA}\}$ is one of the key predictors of health in the prevention of civilization diseases, including cardiovascular diseases $[6,7]$. This was the basis for developing guidelines to minimize the risk of these diseases $[8,9]$. In relation to patients with cardiovascular diseases, the optimum level of physical activity recommended by cardiologists, taking into account the type of disease and condition of the patient, is one of the factors which affect treatment efficacy [10]. This constituted the basis for developing guidelines for the training of people with cardiac diseases [11]. The experiences of physicians and physiotherapists show frequent problems, mostly due to excessive mobility of rehabilitated patients [12]. These problems affect both the 
immediate post-hospital rehabilitation, and PA conceived as part of a healthy lifestyle. Solving these problems requires defining PA barriers. In the psychological aspect they are referred to as "fear of movement" - kinesiophobia [13].

The term "kinesiophobia" was first used by Kori et al. to determine the fear of movement due to lower back pain [14]. These authors identified this fear as excessive, irrational, and consequently adverse to health due to reduced activity. The universality of the definition of kinesiophobia has led to its use in relation to many other illnesses with the accompanying fear of movement. The Tampa Scale for Kinesiophobia (TSK) - a tool designed to measure and explain this problem, finds its application in relation to other illnesses. The importance of the problem of reduced motor activity in the prophylaxis and treatment of many diseases, has resulted in numerous adaptations of the diagnostic tool, both for the disease and for linguistic and cultural versions. $[15,16,17,18]$. This also applied to cardiovascular diseases $[19,20,21]$. The significance of the problem and encouraging results of several studies led to the wider use of this tool, which also applies to people suffering cardiologically in Poland, where this problem is poorly understood. This was the inspiration to undertake research on an explanation for the reasons for the limitation in the activation of cardiac patients.

\section{OBJECTIVE}

The purpose of the study was to determine the level of kinesiophobia (fear of movement) in patients with cardiovascular diseases at various stage of disease, and to assess its possible associations with declared physical activity, socio-demographic determinants and morbidity. It was also decided to examine the internal consistency of the tool used to measure kinesiophobia.

\section{MATERIALS AND METHOD}

The study included 217 patients with cardiovascular diseases: 94 women (43.3\%) and 123 men (56.7\%), hospitalized in the Department of Cardiology in Katowice (southern Poland) during a period of 6 months in 2017. Other selection criteria included: voluntary participation and sufficient mental fitness (contact with the patient, lack of cognitive disorders) to understand questions and statements in the questionnaire. In order to obtain complete data, the persons conducting the research supported the respondents in the ase of emerging doubts. Due to the objective of the study, an additional criterion was adopted: professional inactivity caused by retirement or pension. The rationale was to exclude the area of "forced" physical activity through professional work.

The research tool was a questionnaire survey that consisted of a metric part, the Polish adapted version of the Tampa Scale for Kinesiophobia Heart (TSK Heart), and the International Physical Activity Questionnaire (IPAQ) - short version. The metric part was designed to determine variables, such as gender, age, morphological parameters (height and weight - based on which the BMI was calculated), size of residence (village, small town $-<50,000$, medium city: 50,000-100,000, big city $>10,000$ ), way of living (alone, only with spouse/ partner, family), education (basic, vocational, secondary, higher), time from diagnosis of cardiovascular disease and its type (infarct, stroke, coronary artery disease, hypertension, heart valve failure, arrhythmias, other cardiovascular diseases), and chronic non-cardiac co-morbidities (as a sum of illnesses). The questionnaire also included questions about the level of fitness - motor independence. Possible answers: I am fit, completely independent; I am not fully fit but independent; I am not fully fit and I need other people's help.

The level of kinesiophobia was determined using the Polish version of the Tampa Scale for Kinesiophobia Heart (TSK Heart). The kinesiophobia scale prepared by the authors, contains 17 statements in which patients respond according to a four-point Likert scale, ranging from 1-4: "I do not agree completely", "I do not agree in part", "I agree partially", "I agree completely". Statements 4, 8, 11 and 12 were coded reversal [22]. In the presented study, the sum of points attributed to each statement was used - higher TSK Heart score meant a higher level of kinesiophobia [23].

Language and merits-related adaptation of the TSK Heart. The original version of the TSK Heart was translated into Polish by two translators in accordance with international guidelines [24]. The next stage was a linguistic and meritsrelated adaptation by a team of experts (translators, cardiologist, physiotherapist, physical activity specialist). The established version was presented to 20 adults of all ages and different education levels, who were asked for full comprehension. Three elderly and low-educated people needed additional explanations, which was a guideline for additional explanations in the course of research for those in need.

Physical activity of the patients was estimated on the basis of the commonly used short version of the International Physical Activity Questionnaire (IPAQ). This tool, based on the researcher's own description, estimates physical activity at three levels of intensity: intense, moderate, and gait activity in the last week. The frequency (number of days per week) multiplied by the time (in minutes) and the intensity index expressed in MET, allow estimation of activity in the mentioned areas. These indicators are: 8 MET for an intensive activity, $4 \mathrm{MET}$ for a moderate activity, and 3.5 MET for gait. The sum of intensive, moderate and gait activities allows the estimation and expression of total weekly activity of an individual in MET-minutes.

Patients were divided into groups according to level of activity <600 MET-min/week - physically passive patients; 600-3,000 MET-min/week - patients moderately active; 3,000 and above MET-min/week - active patients [25]. The assessment of physical activity concerned the period before the hospital stay.

Statistical analysis. Descriptive statistics of the evaluated variables were calculated: mean values, standard deviation (SD), and confidence intervals for mean values (CI $\pm 95 \%)$. Taking into account the number of respondents, genderbased comparisons were made using ANOVA variance analysis. The relationships between variables were calculated using Pearson's correlation coefficients (r-). In other cases, nonparametric statistics were used. For comparison of two groups, the U Mann-Whitney test, and when there were more groups, the Kruskal-Wallis ANOVA was used. The accepted level of significance was $\mathrm{p}<.05$. Statistical analyzes were performed using the STATISTICA 13.1 package. 


\section{RESULTS}

First, the internal consistency of the TSK Heart was examined. The calculated alpha-Cronbach factor (AC) was 0.77 , with an average correlation between positions of 0.42 . The calculated half reliability was: $\mathrm{AC}=0.91$, mean $\mathrm{r}=0.37$. This allowed the TSK Heart to be considered as internally consistent.

Comparisons of age, BMI, TSK Heart scores and total IPAQ activity did not show gender differences (Tab. 1). These results allowed the exclusion of gender from further analyzes, and in this case, to treat the test group as homogeneous.

Table 1. Descriptive statistics: age, BMI, TSK Heart, IPAQ; gender differences (ANOVA) and correlation coefficients from TSK Heart and IPAQ

\begin{tabular}{|c|c|c|c|c|c|c|}
\hline Variable & Gender & Mean (SD) & $\mathrm{Cl} \pm 95 \%$ & $\mathrm{p}$ & $\begin{array}{c}r-\text { TSK } \\
\text { Heart }\end{array}$ & $r-I P A Q$ \\
\hline \multirow{2}{*}{$\begin{array}{l}\text { Age } \\
\text { (years) }\end{array}$} & $\mathrm{K}$ & $68.10(6.96)$ & $66.67-69.52$ & \multirow{2}{*}{0.285} & \multirow{2}{*}{$0.223^{* *}$} & \multirow{2}{*}{$-0.368^{* * *}$} \\
\hline & M & 66.85 (9.44) & $65.17-68.54$ & & & \\
\hline \multirow{2}{*}{$\begin{array}{l}\text { BMI } \\
\left(\mathrm{kg} / \mathrm{m}^{2}\right)\end{array}$} & K & $29.38(5.66)$ & $28.22-30.54$ & \multirow{2}{*}{0.394} & \multirow{2}{*}{0.165} & \multirow{2}{*}{-0.077} \\
\hline & $M$ & $28.79(4.48)$ & $28.79-29.59$ & & & \\
\hline \multirow{2}{*}{$\begin{array}{l}\text { TSK } \\
\text { Heart } \\
\text { (points) }\end{array}$} & K & $43.93(9.32)$ & $41.93-45.93$ & \multirow[b]{2}{*}{0.696} & & \multirow[b]{2}{*}{$-0.558^{* * *}$} \\
\hline & M & $43.36(10.85)$ & $41.32-45.39$ & & & \\
\hline \multirow{2}{*}{$\begin{array}{l}\text { IPAQ } \\
\text { (MET } \\
\text { thous.) }\end{array}$} & K & $1.518(1.12)$ & $1.28-1.76$ & \multirow[b]{2}{*}{0.402} & \multirow[b]{2}{*}{$-0.558^{* * *}$} & \\
\hline & M & $1.664(1.29)$ & $1.42-1.91$ & & & \\
\hline
\end{tabular}

Data are presented as mean (SD). ** $p=0.01 ;{ }^{* * *} p=0.000$

The proportion was calculated of people who, according to the Vlaeyen et al. criteria, obtained more than 37 points on the TSK Heart scale, [23]. These authors have identified this cutoff as a high indicator of kinesiophobia. In the presented study group, there were 158 people with such an indicator, which accounted for $72.81 \%$ of all patients.

Table 2 shows characteristics of patients with cardiovascular disease, including the declared level of physical activity. and the combination of numbers and percentages of patients with high indicator of kinesiophobia.

Table 2. Descriptive statistics of patients according to their activity levels, including patients with high kinesiophobia indicator

\begin{tabular}{|c|c|c|c|c|c|c|}
\hline \multirow[t]{2}{*}{ ACTIVITY LEVEL } & \multirow[t]{2}{*}{$\mathrm{N}$} & \multirow[t]{2}{*}{$\%$} & \multirow[t]{2}{*}{ Mean (SD) } & \multirow[t]{2}{*}{$\mathrm{Cl} \pm 95 \%$} & \multicolumn{2}{|c|}{$\begin{array}{c}\text { TSK } \\
\text { Heart>37 }\end{array}$} \\
\hline & & & & & $n$ & $\%$ \\
\hline $\begin{array}{l}\text { Passive: } \\
\text { < } 600 \text { MET-min./week }\end{array}$ & 58 & 26.73 & $\begin{array}{c}354.79 \\
(126.37)\end{array}$ & $\begin{array}{l}314.37- \\
395.20\end{array}$ & 53 & 91.38 \\
\hline $\begin{array}{l}\text { Moderate: } \\
600 \text { - } 3000 \text { MET-min./week }\end{array}$ & 129 & 59.45 & $\begin{array}{l}1439.00 \\
(615.17)\end{array}$ & $\begin{array}{c}1331.83- \\
1546.17\end{array}$ & 95 & 73.64 \\
\hline $\begin{array}{l}\text { Active: } \\
\text { >3000 MET-min./week }\end{array}$ & 30 & 13.82 & $\begin{array}{l}3957.10 \\
(695.08)\end{array}$ & $\begin{array}{c}3697.55- \\
4216.65\end{array}$ & 10 & 33.33 \\
\hline
\end{tabular}

Socio-demographic variables (as grouping variables) did not differentiate between either kinesiophobia-TSK Heart or IPAQ. Only the level of fitness (motor independence) was a variable which differentiated both TSK Heart and IPAQ at a statistically significant level (Tab. 3). Comparisons showed differences between the group of people who were completely fit and those who are not fully fit - who needed help from others. The difference levels were for TSK Heart: $P=0.019$, for IPAQ: $P=0.032$ (Fig. 1).
Table 3. Characteristics of study group including comparison of TSK and IPAQ - due to sociodemographic variables and physical efficiency (Kruskal - Wallis ANOVA)

\begin{tabular}{lcccc}
\hline \multirow{2}{*}{ Grouping variable } & \multicolumn{2}{c}{ TSK Heart } & \multicolumn{2}{c}{ IPAQ } \\
\cline { 2 - 5 } & $H$ & $p$ & $H$ & $p$ \\
\hline Place of residence & 1.195 & 0.754 & 1.739 & 0.628 \\
\hline Way of living & 0.351 & 0.839 & 4.335 & 0.114 \\
\hline Education & 2.563 & 0.464 & 5.273 & 0.153 \\
\hline Level of efficiency & 8.938 & $0.011^{*}$ & 8.093 & $0.017^{*}$ \\
\hline
\end{tabular}

Data are presented as mean (SD). ${ }^{*} p<0.05$

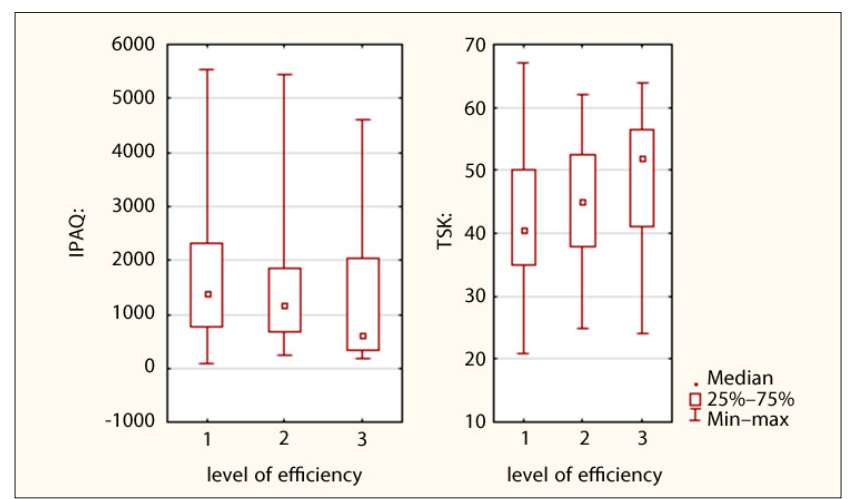

Figure 1. Activity and kinesiophobia - groups according to efficiency

Relations of co-morbidities (other than cardiovascular diseases) with kinesiophobia and activity were investigated by comparing patients without co-morbidities $(n=144)$ with patients with co-morbidities $(\mathrm{n}=73)$. The $\mathrm{U}-\mathrm{MW}$ test showed no difference. Suitably for TSK Heart: $P=0.464$, for IPAQ: $P=0.232$.

Conducted analyzes have suggested the need for further investigation of cardiovascular diseases relations with kinesiophobia and physical activity. Evaluation of the correlation of time elapsed since the diagnosis of cardiovascular disease with TSK Heart $(r=-0.040)$ and IPAQ $(\mathrm{r}=-0.082)$, and correlations of the time of detection of the condition with TSK Heart $(r=0.056)$ and IPAQ $(r=-0.062)$, did not show such a dependence.

Analysis was also performed of kinesiophobia and PA, taking into account individual cardiovascular diseases diagnosed in the study group (Tab. 4).

\section{DISCUSSION}

The problem of the PA barrier is not new [26]. Negative physical, mental and social consequences of motor passivity are increasingly recognized $[27,28]$. In the general dimension, the source of physical passivity is to be found in the increasing number of civilization facilities "inclining" to motor passivity [29].

Different approaches are involved in the problem of mobility. Some researchers distinguish so-called external PA barriers (individually independent) and internal PA [30,31]. This division is challenged by authors who believe that passive sources should be sought only in personality traits [13].

The TSK Heart used in this study has a clearly clinical profile $[17,32]$ indicating disease as a major cause of kinesiophobia (fear of movement), and the number of results obtained seem to confirm this. First of all, the percentage of people whose TSK Heart score was above the cut-off point [23] constitutes 
Table 4. Characteristics of study group of patients taking into account the type of cardiovascular disease, TSK Heart and IPAQ descriptive statistics and TSK Heart-IPAQ correlations

\begin{tabular}{|c|c|c|c|c|c|c|c|}
\hline \multirow{2}{*}{ DISEASE } & \multirow{2}{*}{$\mathrm{N}$} & \multirow{2}{*}{$\begin{array}{l}\% \text { of } \\
\text { total }\end{array}$} & \multicolumn{2}{|c|}{ TSK Heart } & \multicolumn{2}{|c|}{ IPAQ (MET thous.) } & \multirow{2}{*}{$\begin{array}{c}r: \\
\text { TSK Heart-IPAQ }\end{array}$} \\
\hline & & & $x(S D)$ & $\%>37$ & $x(S D)$ & $\%<0.600$ & \\
\hline Myocardial infarction & 72 & 33.33 & $46.68(9.84)$ & 81.94 & $1.369(1.067)$ & 26.39 & $-0.428^{* * *}$ \\
\hline Stroke & 18 & 8.29 & 49.71 (9.59) & 88.89 & $1.135(1.081)$ & 50.00 & $-0.868 * * *$ \\
\hline Coronary disease & 130 & 59.91 & $44.31(10.14)$ & 76.15 & $1.545(1.116)$ & 27.69 & $-0.523^{* * *}$ \\
\hline Hypertension & 119 & 54.84 & $44.44(9.40)$ & 76.47 & $1.509(1.074)$ & 27.73 & $-0.410^{* * *}$ \\
\hline Rhythm disorders & 86 & 39.63 & $43.28(9.63)$ & 69.77 & $1.660(1.267)$ & 25.58 & $-0.563^{* * *}$ \\
\hline Other cardiovascular diseases & 15 & 6.91 & $44.21(11.77)$ & 66.67 & $2.207(1.714)$ & 26.67 & $-0.663^{* *}$ \\
\hline
\end{tabular}

Data are presented as mean (SD). ** $p=0.01 ; * * * 0=0.000$

the major extent of the phenomenon, and the correlation TSK Heart - IPAQ (Tab. I) confirms the negative effect of disease on the PA. In addition to the percentage of patients with a TSK Heart score greater than 37, there are no TSK Heart differences in gender and no correlation with BMI (Tab. I). The analysis did not show the influence of socio-demographic variables, neither on kinesiophobia nor on PA (Tab. 2). There were no differences in comparison of patients with coexisting illnesses with those without coexisting conditions. The main factor was the occurrence of cardiac disease itself, not the period after the onset of symptoms or duration of the illness (time elapsed from diagnosis).

There are several cardiac conditions where increased physical activity should be restricted or even contraindicated. These are primarily acute conditions: acute myocardial infarction or its suspicion, active endocarditis, myocarditis and pericarditis, acute systemic and febrile illness, unstable angina, uncontrolled arrhythmias and conduction disorders, decompensated heart failure, aortic dissection aneurysm, lung disease in the period of respiratory failure, thrombophlebitis, decompensated arterial hypertension (systolic at rest $>180$ $\mathrm{mmHg}$, diastolic $>110 \mathrm{~mm} \mathrm{Hg}$ ), cerebral focal symptoms in the last three months, or other conditions requiring intensive supervision of the patients [4].

However, after pharmacological or interventional stabilization of the patient, the efficacy of therapy requires the use of stepwise cardiac rehabilitation, where the use of optimum PA plays a key role, and a number of studies have demonstrated its effectiveness [33]. Although the benefits of exercise in secondary cardiovascular disease prevention seem to be unmistakable, their type, duration, and intensity are still at the research stage, and developing appropriate patient care and treatment options requires long-term follow-up [34].

It seems that the effectiveness of any preventive activity will be conditioned by the diagnosis of the level of kinesiophobia, which also requires further research [13]. It will also be important to properly implement systematic desynthesis $[35,36]$, which may require the cooperation of physicians, physiotherapists and psychologists.

Limitations of the study. This study has a number of limitations resulting from its pilot and cross-sectional nature, aimed at examining the significance of the problem. These limitations concern the number of examined persons and the inability to test over time the consistency of the measurement tools used.

\section{CONCLUSIONS}

Kinesiophobia measured by the TSK Heart is common in patients with cardiovascular disease and applies to the majority of patients. The lack of kinesiophobia associations with gender, age, BMI and socio-demographic variables indicate the disease as its main cause. Regardless of the type of cardiovascular disease, kinesiophobia negatively affects the level of physical activity. The quality of life of patients with cardiovascular diseases and the effectiveness of cardiological rehabilitation are conditioned by physical activity, while breaking its barriers requires further research.

Ethics approval. The study was approved by the Bioethical Committee of the Medical University of Silesia in Katowice (Resolution No. KNW/0022/KBI/98/15).

Conflicts of Interest. The authors declare no conflict of interest, neither financial nor non-financial, and was entirely self-financed. The design of the study, collection, analyses, interpretation of data, writing of the manuscript, and decision to publish the results were performed only by the authors. The study does not contain data from any individual person and data obtained from the questionnaires is freely available upon request.

\section{REFERENCES}

1. Cierniak-Piotrowska M, Marciniak G, Stańczak J. Statistics of deaths and mortality due to cardiovascular diseases. GUS Warszawa 2016. p 1-28.

2. European Cardiovascular Disease Statistics http://www.ehnheart.org/ cvd-statistics.html (access: 2017.07.7).

3. WHO Cardiovascular disease. http://www.who.int/cardiovascular_ diseases/en/ (access: 2017.07.7).

4. Karolewska-Kuszej M, Brodowski L. Kompleksowa rehabilitacja u pacjentów z chorobami układu krążenia. Forum Kardiologów. 2005; 10; 4 : 111-114.

5. Deskur-Śmielecka E, Jóźwiak A, Dylewicz P. Rehabilitacja kardiologiczna u osób w podeszłym wieku. Kardiol Pol. 2008; 66; 6: 684.

6. Batty GD. Physical activity and coronary heart disease in older adults. A systematic review of epidemiological studies. Eur J of Public Health. 2002; 12: 171-176.

7. Löllgen H, Bachl N. Cardiovascular prevention and regular physical exercise: Activity and training as the true "polypill". Herz. 2016; 41; 8: 664-670.

8. Piepoli MF, Hoes AH, Agewall A, et al. 2016 European Guidelines on cardiovascular disease prevention in clinical practice Kardiol Pol. 2016; 74; 9:821-936.

9. Haskell WL, Lee IM, Pate PR, et al. Physical Activity and Public Health: Updated Recommendation for Adults From the American College of 
Sports Medicine and the American Heart Association. Circulation. 2007; 116: 1081-1093.

10. Smarż, K. Cardiac rehabilitation in various clinical situation - phases, indications, contraindications, risks and safety issues. Borgis - Postępy Nauk Medycznych. 2008; 10: 643-652.

11. Piepoli MF, Conraads V, Corrà U, et al. Exercise training in hear failure: from theory to practice. A consensus document of the Heart Failure Association and the European Association for Cardiovascular Prevention and Rehabilitation. Eur J Heart Fail. 2011; 13; 4: 347-57

12. Beswick AD, Rees K, West RR, et al. Improving uptake and adherence in cardiac rehabilitation: literature review. J Adv Nurs. 2005; 49; 5 : $538-555$

13. Knapik A, Saulicz E, Gnat R. Kinesiophobia - introducing a new diagnostic tool. J Hum Kinet. 2011; 28: 25-31.

14. Kori SH, Miller RP, Todd DD. Kinesiophobia: A new view of chronic pain behavior. Pain Management. 1990; 3: 35-43.

15. Kushi LH, Doyle C, McCullough M, et al. American Cancer Society Guidelines on Nutrition and Physical Activity for Cancer Prevention. Cancer J Clin. 2006; 56: 254-281.

16. Houben RMA, Leeuw M, Vlaeyen JWS, et al. Fear of Movement/ Injury in the General Population: Factor Structure and Psychometric Properties of an Adapted Version of the Tampa Scale for Kinesiophobia. J Behav Med. 2005; 5; 28: 415-424.

17. Roelofs J, Sluiter JK, Frings-Dresen MH, et al. Fear of movement and (re)injury in chronic musculoskeletal pain: Evidence for an invariant two-factor model of the Tampa Scale for Kinesiophobia across pain diagnoses and Dutch, Swedish, and Canadian samples. Pain. 2007; 131: 181-190.

18. Koho P, Borodulin K, Kautiainen H, et al. Finnish version of the Tampa Scale of Kinesiophobia: Reference values in the Finnish general population and associations with leisure-time physical activity. J Rehabil Med. 2015; 47; 3: 249-255.

19. Bäck M. Exercise and Physical Activity in relation to Kinesiophobia and Cardiac Risk Markers in Coronary Artery Disease. University of Gothenburg Gothenburg 2012.

20. Bäck M, Cider A, Herlitz J, et al. The impact on kinesiophobia (fear of movement) by clinical variables for patients with coronary artery disease. Int J Cardiol. 2012; doi:10.1016/j.ijcard.2011.12.107

21. Acar S, Savci S, Keskinoğlu P, et al. Tampa Scale of Kinesiophobia for Heart Turkish Version Study: cross-cultural adaptation, exploratory factor analysis, and reliability. J Pain Res. 2016; 9: 445-451.
22. Brunetti ND, Guerra A, Ieva R, et. al. Scared for the scar: fearsome impact of acute cardiovascular disease on perceived kinesiophobia (fear of movement). Clin Cardiol. 2017; 40; 7: 480-484.

23. Vlaeyen JW, Kole-Snijders AM, Boeren RG, van Eek H. Fear of movement/(re)injury in chronic low back pain and its relation to behavioral performance. Pain. 1995; 62;: 363-372.

24. Newmark P. Approaches to Translation. New York; London: Prentice Hall MacMillan 1995.

25. Biernat E, Stupnicki R, Gajewski A. International Physical Activity Questionnaire (IPAQ) - Polish version. Physical Education and Sport. 2007; 51; 1: 47-54.

26. O'Neill K, Reid G. Perceived barriers to physical activity by older adults. Can J Public Health. 1991; 82; 6: 392-396.

27. Pugh ME, Buchowski MS, Robbins, IM, et al. Physical activity limitation as measured by accelerometry in pulmonary arterial hypertension. Chest. 2012; 142; 6: 1391-1398.

28. Vasudevan V, Rimmer J, Kviz F. Development of the Barriers to Physical Activity Questionnaire for People with Mobility Impairments. Disabil Health J. 2015; 8; 4: 547-556.

29. Saulicz M, Saulicz E, Knapik A, et al. Impact of physical activity and fitness on the level of kinesiophobia in women of perimenopausal age. Menopause Reviev. 2016; 15; 2: 104-111.

30. Daskapan A, Tuzun EH, Eker L. Perceived barriers to physical activity in university students. J Sports Sci Med. 2006; 5: 615-620.

31. Gómez-López M, Gallegos AG Extremera, AB. Perceived barriers by university students in the practice of physical activities. J Sports Sci Med. 2010; 9: 374-381.

32. Woby SR, Roach NK, Urmston M, Watson PJ. Psychometric properties of the TSK-11: A shortened version of the Tampa Scale for Kinesiophobia. Pain. 2005; 117: 137-144

33. Cieślik B. Physical and psychological effects of cardiac rehabilitation - literature review. Acta Bio-Optica et Informatica Medica. 2016; 22; 2: 71-97.

34. Darden D, Richardson C, Jackson CA. Physical Activity and Exercise for Secondary Prevention among Patients with Cardiovascular Disease. Curr Cardiovasc Risk Rep. 2013; 7; 6. doi: 10.1007/s12170-013-0354-5.

35. Wolpe J. Psychotherapy by reciprocal inhibition. Palo Alto, CA: Stanford University. 1958.

36. Dubort G. Part12. Systematic desentization. Can Fam Physician. 2011; 57; 11: 1299.

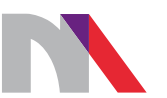

Ministry of Science and Higher Education

Republic of Poland

Generation of the DOI (Digital Object Identifier) - task financed under the agreement No. 618/P-DUN/2019 by the Minister of Science and Higher Education 